\title{
Elementary Teacher Candidates' Flexibility with Comparing Fractions
}

\author{
Daniel R. Ilaria* \\ Secondary Education Department, West Chester University, 725 S. Church Street, West Chester, PA, USA \\ E-mail: dilaria@wcupa.edu \\ Thomas P. Dick \\ Mathematics, Oregon State University, Kidd 108D, Corvallis, OR, USA \\ E-mail: tpdick@math.oregonstate.edu \\ Gail Burrill \\ Mathematics Education, Michigan State University, 224, North Kedzie, East Lansing, MI, USA \\ E-mail: burrill@msu.edu
}

\begin{abstract}
The teaching and learning of fractions have been persistent challenges, and data on national assessments continue to show students' difficulties with fractions. The Common Core State Standards have provided a new lens for the study of fractions, and with it a need to update teacher candidates' mathematical knowledge for teaching. Fractions are a challenge for mathematics teacher educators working with teacher candidates. Exploring instructional approaches to building teacher candidate understanding is important. Technology could play an important role in building robust teacher candidates' conceptual understanding of fractions. Whitacre \& Nickerson's (2016) framework provides background knowledge for exploring whether technology can promote flexible strategies for comparing fractions. In this study, we examine the impact on teacher candidates' flexibility with solving fraction comparison problems through the use of a sequenced set of interactive dynamic technology-based learning experiences modeling the approach advocated in the Common Core Standards.
\end{abstract}

Keywords: fractions, technology, elementary teacher

DOI: $10.7176 / \mathrm{JEP} / 11-9-01$

Publication date:March $31^{\text {st }} 2020$

\section{Introduction}

On the 2004 National Assessment of Educational Progress (NAEP), 50\% of $8^{\text {th }}$ graders could not order three fractions from least to greatest, and 70\% of 17-year-olds could not write 0.029 as a fraction (Siegler et. al., 2010, p. 6). The topic of fractions is considered one of the most challenging for mathematics teacher educators in their work with teacher candidates and in-service teachers (Tirosh, 2000; Borko et al, 1992), whose own knowledge of fractions may be limited (Ball, 1990; Ma, 1999). Studies on teacher candidates' thinking about fractions show they have similar misunderstandings to students (e.g. Osana \& Royea, 2011, Post et. al., 1993).

With their publication, the Common Core State Standards (National Governors Association, 2010) promoted a shift in the study of fractions from an emphasis on part-whole relationship to an emphasis on unit fractions and fractions as numbers on the number line. The changes are supported by a 2010 U.S. Department of Education's Institute of Education Sciences (IES) report on effective K-8 fraction instruction (Siegler, et. al., 2010) and the 2008 study by the National Mathematics Advisory Panel (National Mathematics Advisory Panel, 2008). The authors of the IES study conclude: "A high percentage of U.S. Students lack conceptual understanding of fractions, even after studying fractions for several years" (Siegler et. al., 2010, p. 6). Other studies (e.g. Ma, 1999; Newton, 2008) support the recommendation of the IES regarding the need for "improving teachers' understanding of fractions and how to teach them" (Siegler, et al. 2010, p. 42).

In this article, we describe two different sets of learning experiences for teacher candidates on their conceptual understanding of comparisons of fractions. This study aims to find out the extent that technology-based instruction can encourage flexibility in solving comparison fraction problems. We try to be explicit in describing the instructional intervention but realize other contextual factors may be at play that we have not thought of in documenting our work. We further describe the results of teacher candidate's work with fraction comparisons in each learning experience, particularly focusing on the flexibility in their thinking. Thus, this article contributes to the literature in two ways: (1) by providing an existence proof that technology can encourage flexibility, and (2) by describing a set of interactive computer documents designed to support the Common Core learning progressions for fractions and relating it to teacher candidate learning experiences.

\section{Background}

Research suggests learning takes place when students engage in concrete experiences, observe reflectively, 
develop abstract conceptualizations based upon the reflection, and actively experiment or test the abstraction (Zull, 2002). This kind of learning is supported when students can be actively involved in choosing and evaluating strategies, considering assumptions, and receiving feedback.

Dynamic interactive math technology provides a special environment in which these kinds of learning opportunities can take place. Traditionally, mathematics learning technologies have been used as a "servant," where the user submits a task request to the technology to create a graph, perform calculations, or generate a table (Dick \& Hollebrands, 2011). In contrast, interactive dynamic math technology can present scenarios where the user can act on virtual mathematical objects, and the setting responds immediately with visually discernible results. If mathematical meanings can be readily ascribed to these actions and consequences, the technology can provide the learner with opportunities to "explore and deepen understanding of concepts" (National Governors Association, 2010). This perspective is supported by a number of studies that suggest the strategic use of technological tools can enhance the development of procedural skills and proficiencies such as problem solving and mathematical reasoning (Kastberg \& Leatham, 2005; Roschelle, et al., 2009, 2010; Suh \& Moyer, 2007).

In such environments, however, the task and role of the teacher are central; the use of interactive technology alone is not sufficient for students to learn. The teacher is the mediator of the interaction between the students, the technology and the learning (Drijvers, 2012, Roschelle, et al., 2010; Suh, 2010). Research about effective use of interactive applets in learning statistical concepts suggests teachers should engage students in activities that help them confront their misconceptions and provide them with feedback (delMas, Garfield, \& Chance, 1999). Allowing students to engage in unfettered "play" with interactive technology is appealing but by itself will not maximize learning opportunities; even a well-designed interactive activity is unlikely to be an effective teaching tool unless students' interaction with it is carefully structured (Lane \& Peres 2006). In addition, students need to discuss observations after an activity to focus on important observations, become aware of missed observations, and reflect on how important observations are connected (Chance et al, 2007).

In this study, we examined teacher candidates' learning of fractions based on two sets of learning experiences: one involving direct instruction, and the other using a sequenced set of interactive dynamic technology-based learning experiences modeling the approach advocated in the Common Core Standards. Our focus was on the flexibility of teacher candidates' solving of fraction comparison problems using technology. Specifically, we asked, can technology-based instruction increase the flexible use of strategies in solving comparison problems for teacher candidates?

In seeking to answer our research question, we hoped to find and present evidence of TCs flexibility through coding strategy use and justification to make a claim about a virtue of technology-based instruction. Specifically, we sought out whether the dynamic interactive math technology used encourages a more flexible and appropriate use of strategies while giving the teacher candidates better ways to justify their work and help future students.

\section{Research Background}

Smith's (1995) work on reasoning about fraction magnitude provides four perspectives, or ways of reasoning, about fraction magnitude. The parts perspective involves fractions as parts of whole. The reference point perspective is based on the number line and uses reference numbers, or benchmarks, when reasoning about fraction magnitude. The transform perspective consists of algorithms, such as finding common denominators or numerators. The components perspective consists of making comparisons, either additively or multiplicatively, either within or between two fractions. These four perspectives provide a framework for categorizing teacher candidates' reasoning about fraction magnitude. Smith's work also found that students who thought flexibly, by employing a variety of strategies, were skilled reasoning about fraction magnitude.

A local instruction theory is the "description of, and rationale for, the envisioned learning route as it relates to a set of instructional activities for a specific topic" (Gravemeijer 2004, p. 107). Nickerson \& Whitacre (2010) outline a local instructional theory for the development of number sense with whole numbers. The theory includes three goals for developing number sense with whole numbers: "students will capitalize on opportunities to use number sensible strategies, will develop a repertoire of resource strategies, and will reason with models to understand and use new number sensible strategies" (p. 249). Building on their work with whole numbers and using Smith's (1995) framework, Whitacre \& Nickerson (2016) extended their local instructional theory to rational numbers, particularly focusing on fraction magnitude. They developed a sequence of learning activities (hypothetical learning trajectory) based on prior work, and as the class moved through the learning activities, the researchers "conjectured that students' reasoning would develop from instructed to constructed strategies" (p. 65). Specifically, they expected students to move from a transform perspective to a parts and complements perspective, building more robust knowledge and reasoning. When students in the study showed use of constructed strategies, the data spoke to changes in flexibility and overall performance on the tasks.

Our work builds from Whitacre and Nickerson's (2016) study by beginning with a similar local instructional theory. Our expected learning route for teacher candidates' work on comparing fractions moved from a standard approach of finding common denominators, typically taught in K-12 schools, to using alternative strategies where 
appropriate, such as distance to/from and common numerators. As in Whitacre and Nickerson's (2016) study, we hoped teacher candidates would use constructed strategies and build a more robust knowledge of strategies to solve comparing fraction problems as evidence the technology-based instruction increased the flexible use of strategies in solving comparison problems.

\section{Description of Learning Experiences}

A hypothetical learning trajectory (HLT) "consists of a learning goal, a set of learning activities, and associated conjectures regarding how students will reason as they engage in the activities (Whitacre \& Nickerson, 2016, p. 63). Our goal with both our traditional and technology-based approaches was for teacher candidates to learn multiple fraction comparison strategies and strengthen their conceptual understanding of fraction magnitude. The availability of a structured set of interactive dynamic math environments led us to wonder how their use could impact teacher candidates' fraction comparison strategies differently than direct instruction of strategies. Therefore, in our HLT, the structured interactive documents became an alternative set of learning activities to provide evidence about whether the technology-based instruction could increase the flexible use of strategies in solving comparison problems for teacher candidates.

\subsection{Description of direct instruction experiences on fraction comparison strategies}

One set of learning experiences involved explicit teaching of comparison strategies based on Whitacre \& Nickerson's (2016) scheme for fraction comparison strategies. Teacher candidates were taught specific comparison strategies with the purpose of expanding their thinking beyond using common denominators.

Whitacre \& Nickerson's (2016) scheme, which modified Smith's (1995) framework, outlines the type of strategies that teacher candidates employed in their learning. A typical example would be displaying a pair of fractions and asking teacher candidates to decide which fraction was larger or smaller and explain their reasoning. Many candidates would initially use a common denominator approach or convert to decimals, which belongs to the transform perspective (Whitacre \& Nickerson, 2016). Next, the teacher candidates would answer a series of questions about the size of the fractions, where to locate them on a number line or if they were larger or smaller than a particular whole number, such as 1 . These questions were meant to introduce different strategies: Parts, interpreting fractions in terms of parts of a whole, Reference Point, reasoning about fractions based on benchmarks, or Components, comparing within or between fractions (Whitacre \& Nickerson, 2016). These particular perspectives guided the types of fractions presented to students in order to precipitate learning about alternative approaches, such as using common numerators, and practice the learned strategies. With this approach teacher candidates learned about fraction comparison directly through lessons that introduced different strategies and allowed for thinking and practice with those strategies.

\subsection{Description of the technology supported learning experiences on fraction comparisons}

The alternative set of experiences involved using interactive dynamic technology consisting of a carefully sequenced set of interactive documents focused on fractions and designed to adhere to the approach advocated by the Common Core State Standards (CCSS). By "interactive" we mean that the document environment allows the learner to "deliberately take a mathematical action, observing the consequences, and reflecting on the mathematical implications of the consequences" (MET II, page 34).

The set of interactive documents considered are collectively titled "Building Concepts: Fractions" and were designed with the belief that interactive dynamic technology could provide powerful affordances to improve mathematics learning (and teaching) of fundamental concepts such as fractions. The CCSSM suggest a coherent and consistent approach to fraction and provided the motivation for exploiting interactive dynamic technology. In particular, the CCSSM Learning Progressions (http://math.arizona.edu/ ime/progressions) served as a kind of blueprint for the design work behind the Building Concepts documents.

Building Concepts: Fractions consists of a series of 15 interactive dynamic files (similar to applets) designed to develop concepts related to fractions and operations with fractions. The development, based on the approach advocated by in the CCSSM, uses area models and number lines to help students visualize the concept of fraction as a number and develop operations and concepts related to the meaning of fraction. For example, figure one shows commentary from the CCSSM Learning Progression document and figures two through five show the dynamic files related to the commentary. 


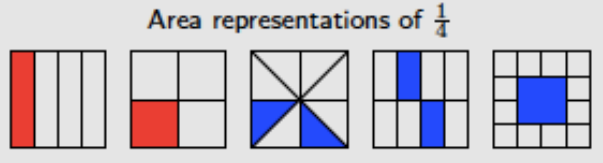

In each representation the square is the whole. The two squares on the left are divided into four parts that have the same size and shape, and so the same area. In the three squares on the right, the shaded area is $\frac{1}{4}$ of the whole area, even though it is not easily seen as one part in a division of the square into four parts of the same shape and size.

Figure 1. CCSS Fraction Progressions.

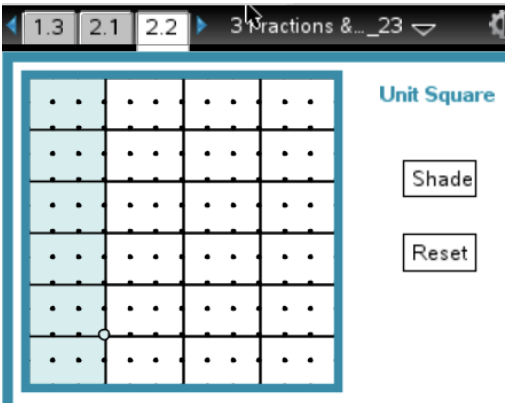

Figure 2. Area models for fractions.

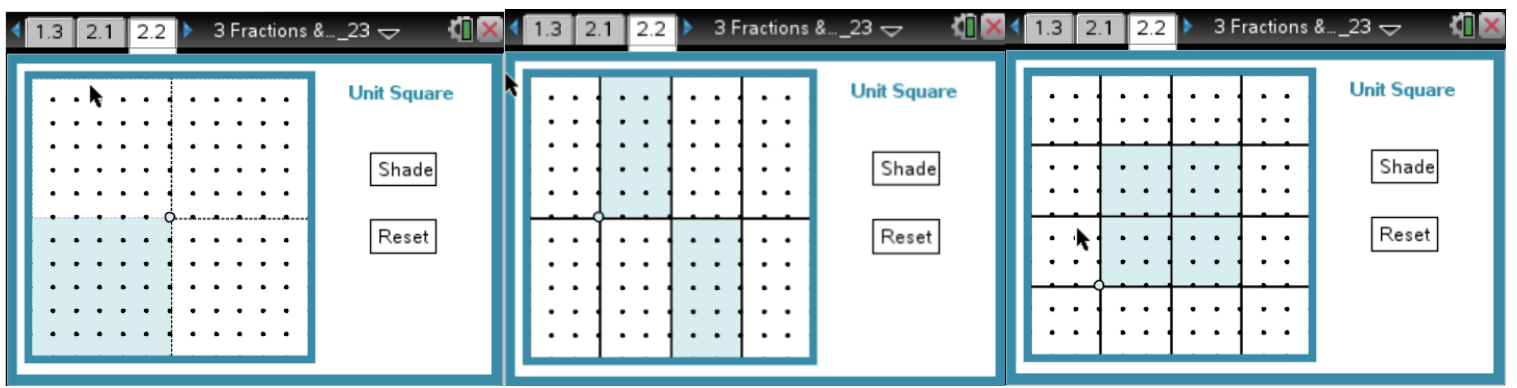

Figures 3, 4, 5. Area models for fractions.

The CCSS expect students to apply and extend previous understandings of multiplication to multiply a fraction or whole number by a fraction. Students build from the concept of area as the product of base and height considering a unit square partitioned into rectangles with fractional side lengths corresponding to unit fractions (figure 6). The area of one rectangle is the product of the base and height but also the size of the unit fraction into which the unit square has been partitioned.

Each document is accompanied by a short facilitator guide that includes: (a) a description of the mathematics that underlies the file; (b) a description of the file and how to use it; (c) possible mathematical objectives for student learning; (d) sample questions for student investigation; and (e) a set of assessment questions that include questions that might be found on the National Assessment of Educational Progress or a high stakes state test.

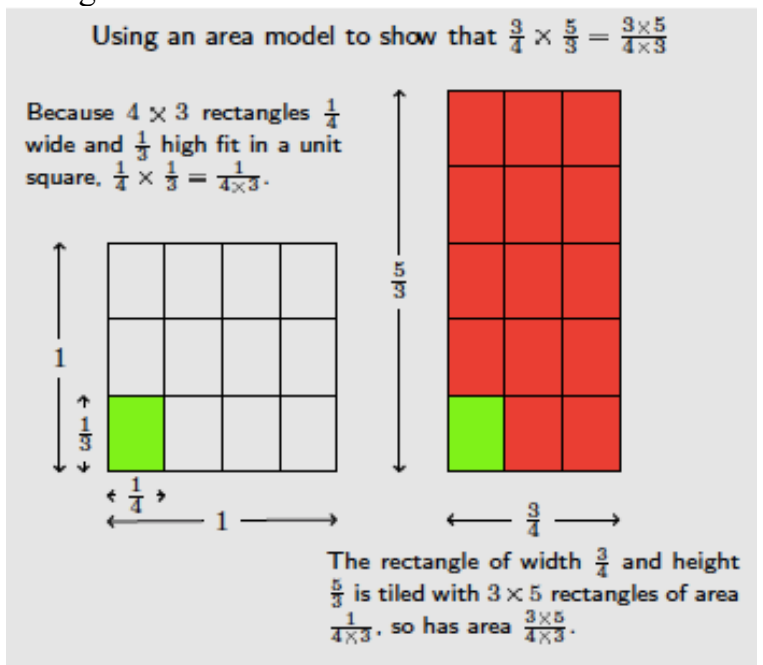

Figure 6. CCSS Fractions Progressions - Multiplication.

The sample questions are intended to give guidance to teachers with respect to inquiry, asking questions that "push" and "probe" student thinking. The questions in the activities are designed to surface and confront student misconceptions such as multiple names for the same fraction, adding numerators and denominators, or confusion about division of fractions (Sowder, Philipp, Armstrong \& Schappelle, 1998; Jigyel \& Afamasaga-Fuata'I, 2007). The questions vary in difficulty; instructors might choose to use only a subset of the questions rather than working through all of them.

The facilitator guides are intended to provide a starting point for activities that can be used with students; the files themselves are typically robust enough to be adapted for learning objectives not mentioned in the guides. The files are designed to give students ways to think about fractions and fraction operations that will allow them to 
develop the necessary fluency with fractions for their continuing work in mathematics, not to provide drill and practice. (E.g. Figures 7 and 8)

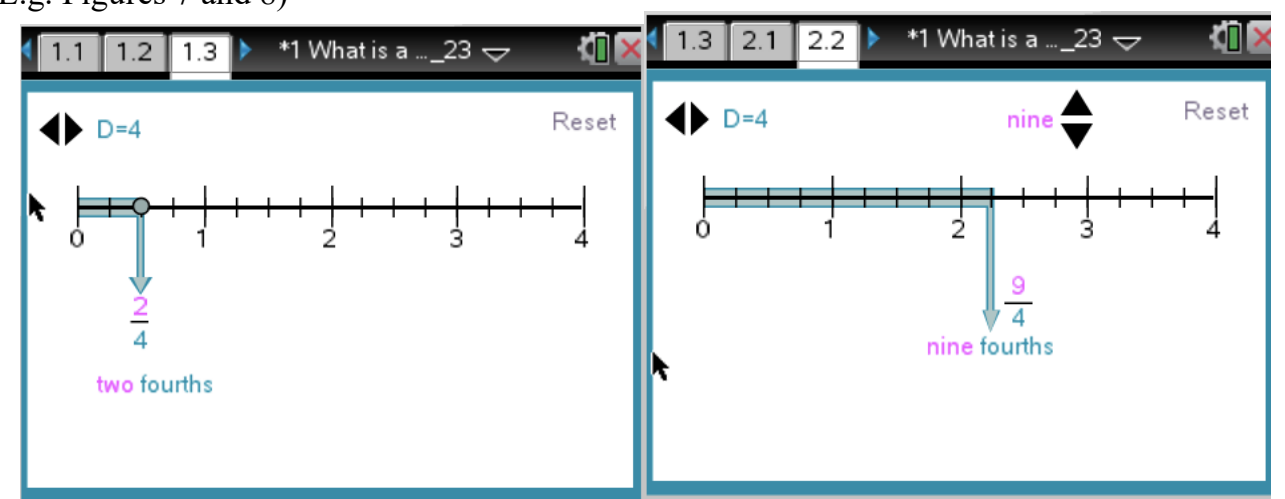

Figures 7. What is a Fraction? Page 1.3

Figure 8. What is a Fraction? Page 2.2.

Note. Clicking the arrow for D changes the number of equal partitions. Dragging the open circle in 1.3 or the vertical arrow in 2.2 determines the number of unit fractions.

The files and questions are intended to help students think of fractions as a number (Mack, 1995), support the transition from words to symbols (Sowder, 1992), recognize that fractions can be larger than 1, understand that whole numbers can be represented as fractions (Siegler \& Pyke, 2012), and recognize a larger denominator does not determine the larger fraction (Fazio, 2012).

The intended audience for Building Concepts: Fractions is those at any level who are teaching or learning fractions or reviewing fraction concepts (elementary, middle school, high school, developmental mathematics courses at the post-secondary level, pre-service mathematics education university courses), parents or anyone interested in learning or helping others learn about fractions. The content in the materials most closely aligns to the grade level Common Core Mathematical content standards for third through sixth grades. (The interactive documents and supporting materials are available for the TI-Nspire platform at https://education.ti.com/en/building-concepts/activities/fractions. )

\section{Methods}

The elementary methods course where the study occurred had been developed over several years through collaboration among mathematics education faculty. The established sequence of topics for fractions begins with contextual problems involving fractions, area, length and discrete models, comparing fractions, and ends with addition, subtraction, multiplication and division operations. In order to develop the technology version of the course the interactive documents were examined to see which activities would align to the existing topics in the non-technology course. The only topics without a direct relationship to the existing content were discrete models and comparing fractions. In order to address this, the technology course used the discrete model activities from the non-technology course. Since several technology activities had questions about comparing fractions embedded in the activities, the decision was made to emphasize these questions or discussions while working with other topics rather than explicitly teaching strategies as done in the non-technology class. These decisions resulted in using 10 of the 15 interactive documents available.

\subsection{Participants and Setting}

The participants in the study include 52 teacher candidates (TC) in an elementary methods course. The course was the third in a sequence for elementary teaching majors and focused on mathematical content and pedagogy appropriate for the K-4 classroom. TCs enrolled in the course were in the second or third year of college and between 19 and 20 years old.

The TCs were in three different classes, which shall be called T1, T2 and NT, of size 10, 17 and 25 respectively. The TCs enrolled in the T1 and T2 sections were all female. The NT section consisted of 20 females and 5 males. Three TCs, who initially enrolled in the course sections, were not included in the study because they dropped the class before the end of the semester. TCs in T1 and T2 met for 75 minutes twice a week, and the NT class met for 50 minutes three times a week. T1 and T2 classes engaged in nine lessons on fractions using the interactive dynamic files and supporting materials modified for teacher candidates, and the NT class engaged in 14 lessons without technology. The first author, who taught eight sections of the course over the previous five semesters, was the instructor for the three sections in this study.

\subsection{Data Collection and Analysis}

Teacher candidates were given a pre-assessment on their fraction content and pedagogical knowledge at the beginning of the course. The content questions consisted of selected NAEP questions, and mathematics education 
faculty members with experience teaching the course developed the pedagogy questions based on established course learning expectations. At the end of the course, the final exam served as the post-assessment and consisted of similar questions aligned to the content and pedagogy topics in the pre-assessment.

Teacher candidates completed the pre-assessment during the third week of the course in a regularly scheduled class meeting. This allowed the initial data to be collected and analyzed before the intervention instruction began in week 9 of the course. The pre-assessment consisted of thirteen questions covering content and pedagogy, and TCs were given 30 minutes to answer any questions they could. We included questions on the pre- and postassessment for our particular focus on differences in how TCs approach fraction comparison tasks and explanations about fraction comparison problems to students. Teacher candidates were asked to determine which fraction was larger for two problems by inserting an inequality symbol in the blank. The two problems were A) $\frac{15}{17}, \frac{15}{27}$ and B) $\frac{5}{12}, \ldots, \frac{7}{9}$. Teacher candidates were also asked for an instructional activity to help a student who noted a fraction was greater than a simplified equivalent fraction, such as $\frac{5}{10}>\frac{1}{2}$.

For coding strategies, we referenced Whitacre \& Nickerson's (2016) modification of Smith's (1995) framework. Several categories were similar, but our learning trajectory focused on teacher candidate's building upon the parts and reference points perspectives of their work. We coded for strategies discussed in class, particularly expecting TCs would demonstrate flexibility in the thinking about fractions:

a) Common denominator - TC compares two fractions by converting one or both of them to have a common denominator.

b) Common numerator - TC compares two fractions by converting one or both of them to have a common numerator

c) Distance to/from - TC compares two fractions by referencing a benchmark fraction and describing how far above or below the fractions are to the benchmark value. When both fractions are less than the benchmark, the fraction that is closer is larger. When both fractions are larger than the benchmark, the fraction that is closer is smaller.

d) Benchmark - TC compares two fractions by referencing a benchmark fraction and explaining that one fraction is smaller and the other fraction is larger than the chosen benchmark. The fraction larger than the benchmark fraction is the larger.

e) Area Model - TC compares two fractions by identifying a unit value (one) and modeling each fraction using an area-based picture, such as a bar model, and partitioning the model to conclude the larger fraction has the larger area.

f) Number line - TC compares two fractions by showing their location on a number line through partitioning of the number line and drawing their conclusion based on the larger fraction being farther to the right on the number line.

g) Benchmark on a Number Line - TC uses a number line to demonstrate the benchmark strategy by partitioning the number line to show where each fraction would be located. The larger fraction is the fraction larger than the benchmark or farther to the right on the number line.

h) Number of Copies - TC compares two fractions with the same denominator by describing the number indicates the number of iterations of the unit fraction with the given denominator.

i) Greater Number/Larger Size - TC compares two fractions by noting one fraction has a larger unit size based on the denominator and the same fraction has more iterations of the unit fraction based on the numerator. The fraction with the large size unit fraction and more iterations is the larger fraction.

When examining the data for the pedagogy question, we used an inductive coding approach by creating codes for the types of activities suggested by TCs. We did keep in mind the types of activities TCs engaged in during class and expected responses that used manipulatives, such as fraction tiles, or models, such as number lines, when examining the data. Initially, area models and number lines were coded for the majority of responses. A second pass separated out number line models to indicate if candidates included strategies with the number line model, such as benchmarking fractions, and separated out area models to indicate when candidates included more specific examples, such as fraction tiles or fraction strips. If strategies emerged from candidates' responses that didn't include an area or number line model, they received a separate code, such as comparison strategies. A few responses not directly related to class activities were coded as other.

\section{Results}

The instruction around fraction comparisons in the technology and non-technology courses was different because the technology activities had questions about comparing fractions embedded in the activities, and the nontechnology course followed the previously developed curriculum. Teacher candidates in the technology courses 
had to describe, by dynamically interacting with a number line or area model, why two fractions were either equivalent or not equivalent in several different activities. In the non-technology course, TCs engaged in one lesson where they learned strategies for comparing fractions other than common denominators. The instruction followed the local instructional theory learning experience by asking teacher candidates to compare a given set of fractions. Many TCs began with the common denominator approach as expected. Next, teacher candidates compared a series of fraction pairs, such as $7 / 9$ and $7 / 30$, to highlight the perspectives in Whitacre \& Nickerson (2016): parts, reference points, and components. Teacher candidates in the NT course learned specific names for strategies: benchmark, distance to/from, greater number/larger size, and common numerators. These strategies were introduced prior to answering questions and were reviewed in subsequent lessons and were part of estimation explanations prior to completing a fraction operation problem. Teacher candidates in the T1 \& T2 courses learned the names of strategies as part of the discussion of the problems in the activities after TCs had answered questions by interacting with the software.

\subsection{Strategies for Comparing Fractions}

In order to determine if there any differences evident in how teacher candidates approached fraction comparison tasks, we examined their responses to the fraction comparison problems on the pre- and post- assessment in order to articulate their employed strategies. The results below discuss the number of TCs answering correctly and describe the strategies used in each environment in order to present and compare TCs' flexibility with comparing fractions.

While very few TCs answered the questions incorrectly on the pre-assessment, A) $\frac{15}{17}, \ldots, \frac{15}{27}$ and B) $\frac{5}{12}, \ldots, \frac{7}{9}$, the explanations for how they determined which fraction was larger varied. For problem A on the pre-assessment, $30 \%$ of the TCs used a common denominator approach. On the post-assessment, no TCs used the common denominator approach. In the non-technology class, $80 \%$ of the TCs used a common numerator approach. In the technology classes, TCs answers varied among many different strategies, which are summarized in Table 1.

Table 1. TCs Comparing Fraction Strategies (Post Assessment)

\begin{tabular}{|l|l|l|l|l|}
\hline Comparing Fraction Strategies & \multicolumn{2}{l|}{$\begin{array}{l}\text { Technology courses } \\
(\mathrm{n}=27)\end{array}$} & Non-technology course \\
& Problem A & Problem B & Problem A & Problem B \\
\hline common numerator & 8 & 0 & 20 & 0 \\
\hline distance to/from & 1 & 0 & 2 & 3 \\
\hline area & 1 & 1 & 0 & 0 \\
\hline number line & 7 & 8 & 2 & 3 \\
\hline benchmark on a number line & 2 & 4 & 0 & 0 \\
\hline benchmark & 3 & 7 & 0 & 10 \\
\hline number of copies & 4 & 3 & 0 & 0 \\
\hline common denominator & 0 & 3 & 0 & 6 \\
\hline greater number/larger size & 0 & 1 & 1 & 3 \\
\hline
\end{tabular}

The most prevalent strategies in the T1 and T2 courses were common numerator and explaining the location of the two fractions on the number line. In their work comparing the fractions, several TCs explained "the number of copies were the same but the sizes of the copies were different". This language is consistent with the language used throughout the activities.

For problem B, $68 \%$ of TCs used a common denominator approach on the pre-assessment. On the postassessment, 3 of $27(11 \%)$ students in the technology classes and 6 of $25(24 \%)$ TCs in the non-technology class used common denominators. The most used strategy in the non-technology class was the benchmark strategy that identified both fractions on either side of one-half. In the technology class, the most frequent strategy was a number line followed by two different variations of a benchmarking strategies. For the varied benchmarking strategies, seven of the TCs stated the fractions were on either side of one-half, and four TCs drew the fractions out on a number line and indicated where one-half was located or noted that one fraction was closer to 1 while the other was closer to zero. The three TCs who used the number of copies strategy explained their reasoning by indicating there were more copies of larger pieces in the ninths than the number of copies in smaller pieces of twelfths.

When explaining their comparison strategy, the TCs in the non-technology class typically named a strategy, such as distance to/from, while most TCs in the technology classes wrote out their thinking, such as two copies of seventeenths is closer than twelve copies twenty-sevenths. TCs in the technology classes also used a larger variety 
of strategies for the same problems than the TCs in the non-technology class. Overall, the explanations of TCs were aligned to their classroom experience. By using comparison ideas within activities rather than learning the strategies as tools separately TCs in the T1 and T2 classes explained their approaches to comparing fractions while TCs in the non-technology classroom used the names of the strategies as an explanation.

\subsection{Instructional Knowledge}

In order to determine if there any differences evident in how teacher candidates would explain fraction comparisons to students, we examined their responses to the fraction comparison teaching task on the pre- and post- assessment in order to articulate their employed strategies. The results below discuss the strategies used in each environment in order to present and compare TCs' flexibility with comparing fractions

When asked for an instructional activity on the pre-test that would help a student who noted a fraction was greater than a simplified equivalent fraction, such as $\frac{5}{10}>\frac{1}{2}, 49$ of $52(94 \%)$ of all TCs suggested having students find common denominators or writing the fraction as a mixed number if the fraction was greater than one. When the same question was asked on the final exam, five of $52(9 \%)$ of all TCs stated finding a common denominator was an appropriate instructional activity. Of those five TCs, two of them also suggested, as a second strategy, students should write the fractions on a number line, and a third stated the student should model the fractions with fraction strips. The suggested instructional activities differed by class based on their course experience (Table 2). Table 2. Suggested Instructional Activity

\begin{tabular}{|l|l|l|l|}
\hline $\begin{array}{l}\text { Technology Class Suggested } \\
\text { Tools }\end{array}$ & $\begin{array}{l}\text { Number of } \\
\text { students } \\
(\mathrm{n}=27)\end{array}$ & $\begin{array}{l}\text { Non-technology Class Suggested } \\
\text { Strategies }\end{array}$ & $\begin{array}{l}\text { Number } \\
\text { students } \\
(\mathrm{n}=25)\end{array}$ \\
\hline Draw on a number line & $15(55.5 \%)$ & Use fraction strips & $5(20 \%)$ \\
\hline Use an area model f using a & $6(22 \%)$ & Use fraction tiles & $6(24 \%)$ \\
\hline $\begin{array}{l}\text { Compare fractions } \\
\text { benchmark }\end{array}$ & $4(15 \%)$ & Use comparison strategies & $3(12 \%)$ \\
\hline Other & $2(7.5 \%)$ & Use a number line & $3(12 \%)$ \\
\hline & & Other & $8(32 \%)$ \\
\hline
\end{tabular}

Since the technology classes, T1 and T2, focused on a number line approach, their suggestions to use a number line or area approach was consistent with their learning experiences. The two TCs in the technology class labeled "other" suggested the student needed to "work on reducing fractions and finding equivalent fractions" and "practice to find common denominators between fractions". In the NT class, the eight TCs labeled "other" in the table include one TC who suggested a length model, one TC who suggested an area model, and the remaining TCs stated a common denominator approach or an inappropriate activity. Overall the instructional activities all of the TCs provided on the post-assessment mirror the types of activities in which TCs engaged during their class sessions.

\section{Discussion}

In this research study, we sought evidence to determine if technology-based instruction could have an impact on the flexibility of TC's ability to solve fraction comparison problems. We used their explanations on comparing fractions problems and a task that required TCs to explain fraction comparisons to students to find the evidence. The opportunity to use a set of interactive documents allowed us to employ a hypothetical learning trajectory with regard to learning how to compare fractions by moving away from direct teaching of strategies. Results from preand post-assessment questions show a shift in TCs fraction comparison strategies regardless of their learning experience. These results are consistent with Whitacre \& Nickerson's (2016) results and are important since teacher candidate number sense and improvement of mathematics content knowledge are challenges of teacher preparation programs (CBMS, 2012).

The descriptive nature of TCs strategies in the technology classes provide evidence of flexibility in thinking about comparing fractions. TCs in the technology class consistently referred to number lines, parts or used reference points, which provides some evidence these teacher candidates had developed a robust knowledge of fraction magnitude related to number lines in addition to the using constructed strategies to solve the comparing fractions problems. The TCs in the non-technology class were more direct with their description by using the names of the strategies learned so while their flexibility increased by using constructed strategies, their explanations did not provide any additional evidence of their knowledge around fraction number sense. These results correspond to the learning experience of the teacher candidates and suggest the technology-based learning experience attributed to the development of TCs' flexibility with solving fraction comparisons. As a result, we argue the interactive nature of technology and embedded learning to compare fractions within other activities appears to have promise for improving TC's flexibility with solving fraction comparison problems and promoting a robust understanding of fraction number sense. There is still more to learn along these lines of investigation, 
particularly by increasing the sample size and conducting robust interviews to provide more data. We encourage further work in this area using these or other interactive environments (e.g. Chinnappan, 2000) to determine how build flexibility with comparing fractions in teacher candidates.

\section{References}

Ball, D. L. (1990). Prospective elementary and secondary teachers' understanding of division. Journal for research in mathematics education, 132-144.

Borko, H., Eisenhart, M., Brown, C., Underhill, R., Jones, D., \& Agard, P. C. (1992). Learning to teach hard mathematics: Do novice teachers and their instructors give up too easily? Journal for Research in Mathematics Education, 23, 194-222.

Chance, B., Ben-Zvi, D., Garfield, J., \& Medina, E. (2007). The role of technology in improving student learning in statistics. Technology Innovations in Statistics Education 1. pp. 1-26. Retrieved from: http://eschlarship.org/uc/item/8sd2t4rr

Chinnappan, M. (2000). Preservice teachers' understanding and representation of equality of fractions in a JavaBars environment. Mathematics Education Research Journal, 12(3), 234-253.

Conference Board of Mathematical Sciences (CBMS). (2012). The mathematical education of teachers II. Washington, DC: Mathematical Association of America.

Dick, T.P., and Hollebrands K.F. (Editors), (2011). Introduction to "Focus in High School Mathematics: Technology to Support Reasoning and Sense Making", National Council of Teachers of Mathematics, Reston, VA.

delMas, R., Garfield, J., \& Chance, B. (1999). A model of classroom research in action: Developing simulation activities to improve students' statistical reasoning. Journal of Statistics Education, 7(3), www.amstat.org/publications/jse/secure/v7n3/delmas.cfm

Drijvers, P. (2012). Digital technology in mathematics education: Why it works (or doesn't). Paper presented for Technology Topic Study Group at the Twelfth International Congress on Mathematical Education. Seoul, Korea

Fazio, L. K., Thompson, C. A., \& Siegler, R. S. (2012, November). Relations of symbolic and non-symbolic fraction and whole number magnitude representations to each other and to mathematics achievement. Talk presented at the Annual Meeting of the Psychonomic Society, Minneapolis, MN.

Gravemeijer, K. (2004). Local instruction theories as a means of support for teachers in reform mathematics education. Mathematical Thinking and Learning, 6, 105-128.

Jigyel, K., \& Afamasaga-Fuata'i, K. (2007). Students' conceptions of models of fractions and equivalence. Australian Mathematics Teacher, 63(4), 17-25. Retrieved from http://www.aamt.edu.au/

Kastberg, S., \& Leatham, K. (2005). Research on graphing calculators at the secondary level: Implications for mathematics teacher education. Contemporary Issues in Technology and Teacher Education, 5(1), $25-37$.

Lane, D. M., \& Peres, S. C. (2006). Interactive simulations in the teaching of statistics: Promise and pitfalls. In A. Rossman and B. Chance (Eds.), Proceedings of the Seventh International Conference on Teaching Statistics. [CD-ROM]. Voorburg, The Netherlands: International Statistical Institute.

Ma, L. (1999). Knowing and teaching elementary mathematics: Teachers' understanding of fundamental mathematics in China and the United States. New Jersey: Erlbaum.

Mack, N. K. (1995). Critical ideas, informal knowledge, and understanding fractions. In J. T. Sowder \& B. P. Schappelle (Eds.), Providing a foundation for teaching mathematics in the middle grades (pp. 67-84). Albany, NY: SUNY Press.

Mathematics Education of Teachers II. (2012). Conference Board of the Mathematical Sciences. Providence RI and Washington DC: American Mathematical Society and Mathematical Association of America.

National Mathematics Advisory Panel. (2008). Foundations for success: The final report of the National Mathematics Advisory Panel. US Department of Education.

National Governors Association. (2010). Common core state standards. Washington, DC.

Nickerson, S.D. \& Whitacre, I. (2010). A local instruction theory for the development of number sense. Mathematical Thinking and Learning, 12(3), 227-252, DOI:10.1080/10986061003689618

Newton, K. J. (2008). An extensive analysis of preservice elementary teachers' knowledge of fractions. American Educational Research Journal, 45, 1080-1110.

Osana, H. P., \& Royea, D. A. (2011). Obstacles and challenges in preservice teachers' explorations with fractions: A view from a small-scale intervention study. The Journal of Mathematical Behavior, 30, 333-352.

Post, T. R., Cramer, K. A., Lesh, R., Harel, G., \& Behr, M. (1993). Curriculum implications of research on the learning, teaching and assessing of rational number concepts. In T. P. Carpenter, E. Fennema, \& T. A. Romberg (Eds.), Rational numbers: An integration of research. (pp. 327-362). Hillsdale, NJ: Erlbaum.

Roschelle, J., Rafanan, K., Bhanot, R., Estrella, G., Penuel, W. R., Nussbaum, M., Claro, S. (2009). Scaffolding group explanation and feedback with handheld technology: Impact on students' mathematics learning. 
Educational Technology Research and Development, 58, 399-419.

Roschelle, J., Shechtman, N., Tatar, D., Hegedus, S., Hopkins, B., Empson, S., Knudsen, J., \& Gallagher, L. (2010). Integration of technology, curriculum, and professional development for advancing middle school mathematics: Three large-scale studies. American Educational Research Journal, 47(4), 833-878.

Siegler, R., Carpenter, T., Fennell, F., Geary, D., Lewis, J., Okamoto, Y., Thompson, L., \& Wray, J. (2010). Developing effective fractions instruction for kindergarten through 8th grade: A practice guide (NCEE \#2010-4039). Washington, DC: National Center for Education Evaluation and Regional Assistance, Institute of Education Sciences, U.S. Department of Education. Retrieved from whatworks.ed.gov/ publications/practiceguides.

Siegler, R. S., \& Pyke, A. A. (2012). Developmental and individual differences in understanding of fractions. Developmental Psychology. Advance online publication. doi:10.1037/a0031200

Smith, J. P, I. I. I. (1995). Competent reasoning with rational numbers. Cognition and Instruction, 13, 3-50.

Sowder, J. T. (1992). Estimation and number sense. In D. A. Grouws (Ed.), Handbook of research on mathematics teaching and learning (pp.371-389). New York: Macmillan.

Sowder, J. T., Philipp, R. A., Armstrong, B. E., \& Schappelle, B. P. (1998). Middle-grade teachers' mathematical knowledge and its relationship to instruction. New York: SUNY Press.

Suh J., \& Moyer, P. S. (2007). Developing students' representational fluency using virtual and physical algebra balances. Journal of Computers in Mathematics and Science Teaching, 26(2), 155-173.

Suh, J. M. (2010). Tech-knowledgy for diverse learners [Technology Focus Issue]. Mathematics Teaching in the Middle School, 15(8), 440-447.

Tirosh, D. (2000). Enhancing prospective teachers' knowledge of children's conceptions: The case of division of fractions. Journal for Research in Mathematics Education, 31, 5-25.

Whitacre, I., \& Nickerson, S. D. (2016). Investigating the improvement of prospective elementary teachers' number sense in reasoning about fraction magnitude. Journal of Mathematics Teacher Education, 19(1), $57-$ 77.

Zull, J. (2002). The art of changing the brain: Enriching the practice of teaching by exploring the biology of learning. Association for Supervision and Curriculum Development, Alexandria, Virginia 